\title{
СОЧЕТАНИЕ ФОРТЕПИАННОГО СОПРОВОЖДЕНИЯ И ПОЭТИЧЕСКОГО ЯЗЫКА В КИТАЙСКОЙ ХУДОЖЕСТВЕННОЙ ПЕСНЕ XXI ВЕКА "НОВАЯ ПЕСНЯ ЛЯН ЧЖУ"
}

\section{THE COMBINATION OF PIANO ACCOMPANYING AND POETICAL LANGUAGE IN THE CHINESE ARTISTIC SONG OF THE XXI CENTURY "NEW SONG LIANG ZHU"}

\section{Qiu Ning}

Summary: The article provides a musicological analysis of the work of the Chinese composer Deng Yao "The New Song of Liang Zhu" (2008) which reveals the interrelationships of modern popular piano accompaniment and poetry (lyrics), Chinese folk tales with high literary value, folk modes (heptatonics) and elements of Chinese opera. This work which has been highly appreciated by experts in the sphere of Chinese national vocal music can attract the attention of both a wide range of Chinese listeners and the Russian musical community.

Keywords: Chinese poetry, folk tales, folk modes, heptatonics, piano accompaniment, modern accompaniment, Chinese opera.

\section{Введение}

"Л ян Шанбо и Чжу Интай" - хорошо известная в Китае народная сказка о любви. В 2006 году "Лян Шанбо и Чжу Интай" была включена в первую партию национальных списков охраны нематериального культурного наследия. В 1958 году Чэнь Ган и Хэ Чжаньхао, которые в то время ещё были студентами Шанхайской консерватории, сочинили одноимённый концерт для скрипки на эту тему. Произведение стало известным во всём мире и позже было переложено для фортепиано соло и фортепианного дуэта. Это произведение часто используется в концертном репертуаре, а также в практике преподавания музыки в китайских консерваториях и педагогических университетах.

"Новая песня Лян Чжу" - это новый тип художественной песни, созданной композиторами Дэн Яо и Хэ Сяньи, а также лирическим сопрано Ван Циншуан на основе народной сказки о любви "Лян Шанбо и Чжу Интай", сочетающей язык поэзии, китайские и зарубежные методы композиции и современные фактуры фортепианного сопровождения. На примере "Новой песни Лян Чжу" мы показываем, как стремительно развивается создание китайской музыки в XXI веке.

\author{
Цю Нин \\ Аспирант, Российский государственный педагогический \\ университет имени А.И. Гериена \\ 1595401882@qq.com
}

Аннотация: В статье проводится музыковедческий анализ произведения китайского композитора Дэн Яо "Новая песня Лян Чжу" (2008), в котором выявляются взаимосвязи современного популярного фортепианного сопровождения и поэзии (лирики), китайских народных сказок с высокой литературной ценностью, народных ладов (гептатоники) и элементов китайской оперы. Это произведение, которое было высоко оценено специалистами в области китайской национальной вокальной музыки, может привлечь внимание как широкого круга китайских слушателей, так и российского музыкального сообщества.

Ключевые слова: китайская поэзия, народные сказки, народные лады, гептатоника, фортепианное сопровождение, современный аккомпанемент, китайская опера.

О "Новой песне Лян Чжу" в Китае было опубликовано ряд статей - несколько статей в контексте изучения техники пения и одна статья о фортепианном сопровождении произведения. Учитывая данный факт, в нашей статье мы проведём углублённый анализ этой работы с точки зрения поэзии, техники композиции и фортепианного сопровождения. Это связано с активным отношением специалистов в области китайского музыкального образования к инновациям и стремлением продвигать и развивать традиционную народную музыку. В то же время, этим произведением мы надеемся привлечь внимание российского музыкального сообщества и осуществить художественный обмен между выдающимися культурами двух стран. Фортепианное сопровождение в данном сочинении достаточно богато, и в этой статье мы дадим его характеристику на основе анализа нотного текста.

\section{Шель статьи}

Распространённость "нежелательных музыкальных форм" в современной социально-культурной жизни вызвала размышления педагогов, и лидерами Китая и России были предложены соответствующие законы и политика в отношении этого явления. В связи с этим автор считает необходимым рекомендовать китайской 
публике новые выдающиеся музыкальные произведения, опирающиеся на культурное наследие, чтобы культивировать национальную эстетику и оптимизировать культуру общества. В данной статье рассматривается "Новая песня Лянчжу" - произведение большой художественной ценности, которое автор рекомендует как для русских музыкантов, так и для широкого круга китайских слушателей.

Материалом для написания этой статьи, помимо нотного авторского текста, послужило видео выступления китайской певицы - сопрано Ван Циншуан [10].

Методы исследования: литературный, исторический и музыкально-теоретический анализ.

\section{Основная часть}

B XXI веке мы переживаем эпоху большого информационного взрыва. Постоянно появляются разнообразные музыкальные формы. Некоторые вульгарные музыкальные формы пробудили бдительность китайских педагогов-музыкантов и композиторов. Упадок и исчезновение традиционной музыки всегда было актуальной проблемой, пути решения которой должны найти китайские педагоги-музыканты. Дэн Яо, выдающийся представитель нового поколения композиторов XXI века, занимает лидирующие позиции в области китайской национальной вокальной музыки и фортепианного аккомпанемента. На протяжении многих лет он придерживался собственной творческой концепции, согласно которой, используя в качестве источника вдохновения китайскую классическую литературу и сочетая западные методы композиции, популярные музыкальные произведения и элементы китайской оперы, создавал большое количество выдающихся национальных вокальных произведений, отвечающих эстетике публики. "Новая песня Лянчжу" является вершиной его многочисленных творений. В 2008 году эта работа была исполнена сопрано Ван Циншуан на XII конкурсе молодых певцов Китая и заняла первое место. Работа получила огромный отклик в китайской музыкальной индустрии [1].

Произведение состоит из трёх частей (ABA'). Первая часть - красивое лирическое Larghetto; вторая часть драматическоe Vivace; третья часть - эмоциональное эхо и кульминация. Самая большая "изюминка" произведения заключается в сочетании аккомпанемента, написанного в западном стиле, и мелодии китайского гептатонического стиля. Эти две ладовых структуры полностью различаются по своему происхождению, поэтому дают две различных музыкальных окраски [2, с. 242], что отражает философский взгляд на “поиск единства в противоречиях", благодаря которому два разных ладовых звучания идеально сочетаются друг с другом.
Тема, вдохновившая композитора, - жалоба главной героини на китайскую феодальную систему брака и жажда свободной любви. Короткое вступление состоит из $3 \mathrm{x}$ мотивов (рис. 1):

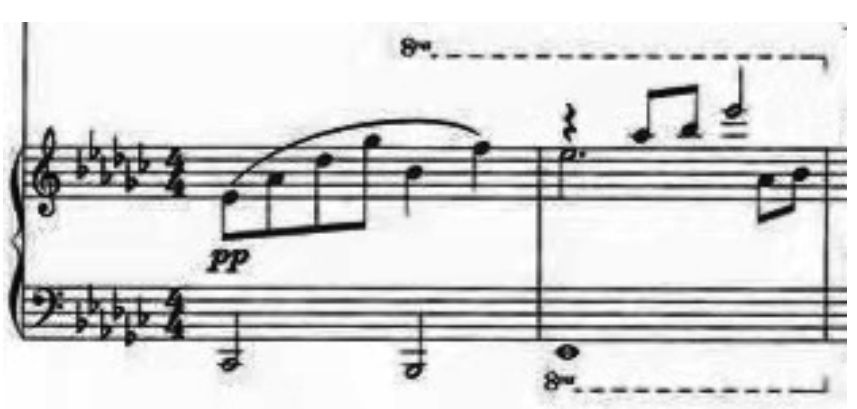

Рис. 1. Вступление к песне.

Основная тональность мелодии базируется на тоне ми-бемоль - "музыка Цин" - в ладу Юй гептатонического стиля, а основная тональность аккомпанемента - мибемоль минор. Использование альтерации ре-бемоль в начале показывает мелодические особенности национального гептатонического стиля. Мелодия аккомпанемента строится на чистых интервалах - кварте и квинте, характеризующих национальный стиль гармонии. Мелодические линии медленно движутся в противоположных направлениях, создавая тихое и пустое пространство с очень слабой динамикой, как будто занавес медленно раздвигается. Мелодия всей вокальной партии раздела А использует типичную китайскую композиционную технику "рыба кусает свой хвост" (рис. 2):

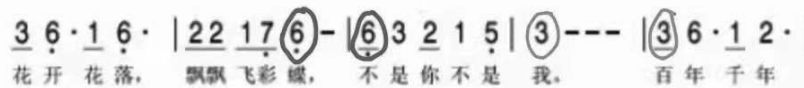

$$
\begin{aligned}
& \underline{2} 5 \underline{7} 1-\left|\underline{6} 3 \underline{2} \frac{10}{71}\right| 6---\left|\underline{3} \underset{6}{6} \cdot \frac{1}{6} \cdot\right| \underline{22} \frac{17}{6}-\mid
\end{aligned}
$$

Рис. 2. Композиционная техника "рыба кусает свой хвост".

На рисунке показан первый вид "укуса хвоста рыбы": в китайской опере, в дуэтах народных песен или инструментальных ансамблях между мотивами последний тон первого предложения (или первого раздела) и первый тон второго предложения (или второго раздела) пересекаются, образуя два тона с различными интервалами, перекрывающими друг друга - эта техника похожа на то, как рыбы кусают друг друга за хвосты, поэтому она получила в народе такое название [3]. Мы можем объяснить эту технику следующим образом: это похоже на двух человек, которые случайно гуляют вместе и когда они видят магазин, заходят туда и прогуливаются; затем они выходят, идут вперёд и встречают следующую достопримечательность. Это требует некоторого воображения, но у него нет цели. 
Рассмотрим фрагмент текста песни - в текстах данного жанра поэзии количество слов от строки к строке постепенно увеличивается, что мы можем наглядно увидеть:

Одной из важных особенностей, отличающих эту композиторскую технику от западных, является её логичность. В западных композиторских техниках развитие темы - будь то полная или частичная имитация или вариация - должно строго поддерживать связь с внешней формой исходной темы (отражение, поступательное движение и т.д.) [4]. В китайской народной музыке имеет музыкальный текст следует словесному тексту (лингвистическое логическое мышление).

\begin{tabular}{|l|c|c|}
\multicolumn{1}{|c|}{ Перевод на русский язык } & $\begin{array}{c}\text { Оригинальный } \\
\text { текст }\end{array}$ & $\begin{array}{c}\text { Количество } \\
\text { иероглифов }\end{array}$ \\
\hline Цветы цветут и опадают & 花开花落 & 4 \\
\hline Порхающие разноцветные бабочки & 飘飘飞彩蝶 & 5 \\
\hline Не ты, нея & 不是你不是我 & 6 \\
\hline Сто лет и тысяча лет & 百年千年 & 4 \\
\hline Любовь подобна длинной реке & 爱如长河 & 4 \\
\hline $\begin{array}{l}\text { Протекающей через тебя и протекаю- } \\
\text { щей через меня }\end{array}$ & 流过你流过我 & 6 \\
\hline
\end{tabular}

Тон фразы "Цветы опадают" ниже, чем тон фразы "Цветы цветут", потому что цветение делает людей счастливыми, а опадание цветов - грустными. Высота тона и эмоциональность каждого предложения взаимосвязаны: они постепенно снижаются, демонстрируя грустное эмоциональное состояние, что показывает нам динамику эмоций.

В аккомпанементе используются популярные гармонии и фактуры. Например, разложенные аккорды используются для описания красивых пейзажей, бабочек, летающих вокруг, когда цветы распускаются и опадают:
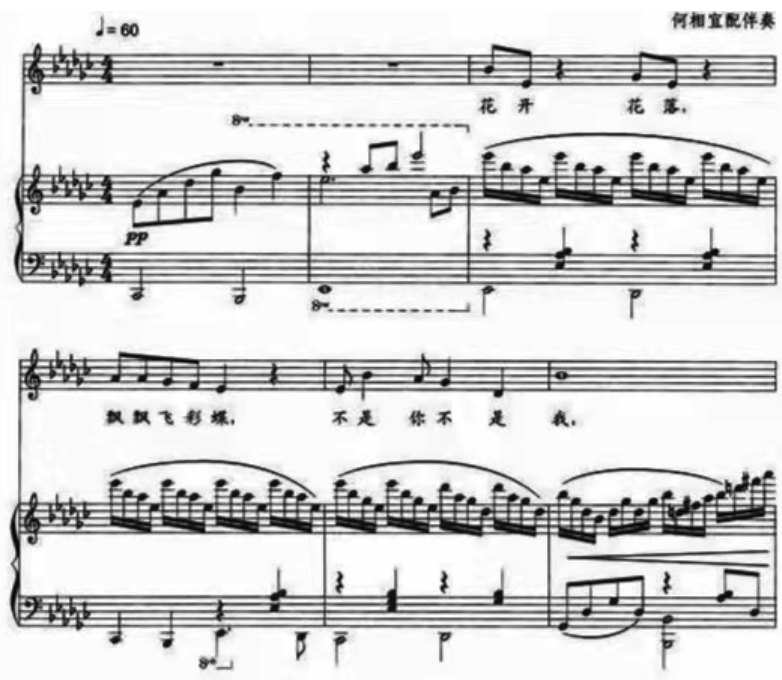

Рис. 3. Фактура начала произведения.
В партии левой руки аккомпанемента применяется метод, часто используемый в китайской популярной музыке - монофонический шаг вниз, что позволяет закрепить окраску гармонии. Данный приём даёт ощущение медленного продвижения своих эмоций в сочетании с нежными эмоциями и красивыми мелодиями.

В мелодии второго предложения используется приём этнической композиции "оставить голову и заменить хвост" - его начало такое же, как и в первом предложении, но окончание другое:

$$
\begin{aligned}
& 25 \underline{7} 1-|\underline{6} 3 \underline{2} \widehat{1071}| 6---|\underline{3} 6 \cdot \underline{1} 6 \cdot| \underline{22} 176-\mid
\end{aligned}
$$

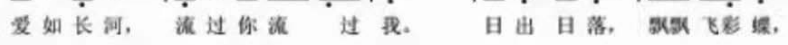

$$
\begin{aligned}
& 6 \widehat{6} \widehat{66}{ }^{8} 7 \cdot \underline{4}|\tilde{3}---| \underline{3} 6 \underline{1} 2-\left|\underline{2} 5 \frac{7}{7} 1-\right|
\end{aligned}
$$

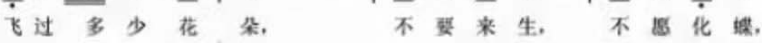

$$
\begin{aligned}
& \text { Рис. 4. Композиционная техника } \\
& \text { "рыба кусает свой хвост". }
\end{aligned}
$$

В то же время, в фактуре аккомпанемента используются компактные аккорды, чтобы вторить певцу в конце его мелодии в том же ритме:

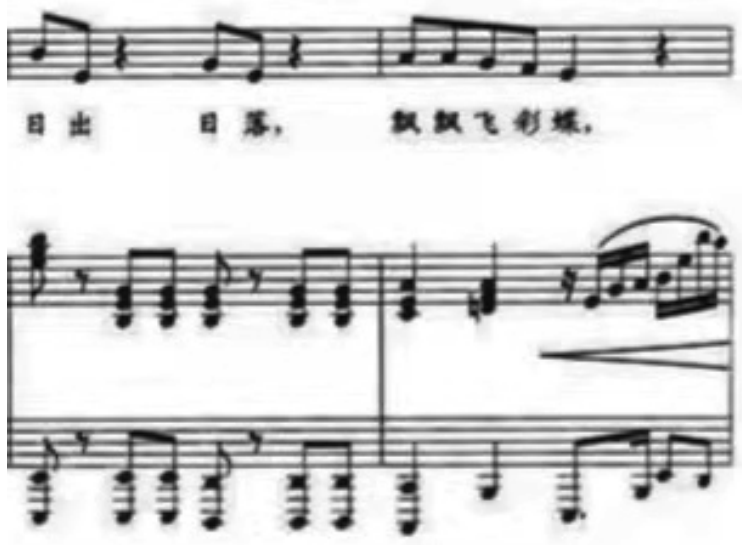

Рис. 5. Диалог голоса и фортепиано во втором предложении.

Это диалог между певцом и концертмейстером, контрастирующий по фактуре с разложенными аккордами предыдущего предложения и предвещающий эмоциональное изменение, которое подчёркивается мелодическим заполнением пассажами в правой руке и ритмическим заполнением в левой руке:

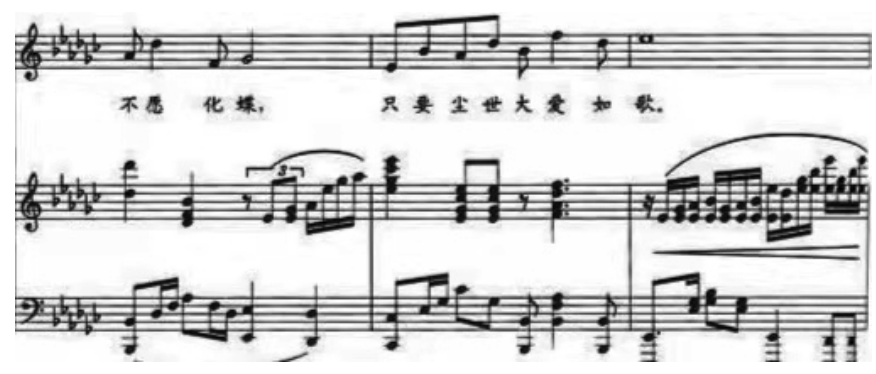

Рис. 6. Трансформация фактуры аккомпанемента.। 
С точки зрения текста песни, мелодию со словами "не хочу оживать (следующее перерождение), не желаю превращаться в бабочек" подчёркивает печальный крик "Не хочу" и “Не желаю”. Мелодия слов "Просто хочу, чтобы земная любовь была похожа на песню" направлена вверх, и высшая точка приходится на слово "Любовь". В "Лекциях по религиозной философии" Г. Гегель упоминает: "Смерть - это сама любовь, и абсолютная любовь проявляется в смерти" [5]. Фактура аккомпанемента здесь богаче, ритмические и тональные фигурации стали плотными и изменчивыми, а эмоции накаляются, композитор многократно использует пентатоническую альтерацию (до-бемоль), который в контексте ми-бемоль минора является тональностью VI ступени. Она создаёт иллюзию мажорной тональности песни и символизирует разрушение феодальной системы брака и стремление к свободной любви.

Конец части А является эмоциональной кульминационной точкой. В этом эпизоде врывается интерлюдия, быстро меняющая музыкальный стиль и задающая характер следующей части. Она показывает изменение эмоций и психологического состояния за счёт изменения ритма и темпа - это уникальная композиционная техника в китайской опере;

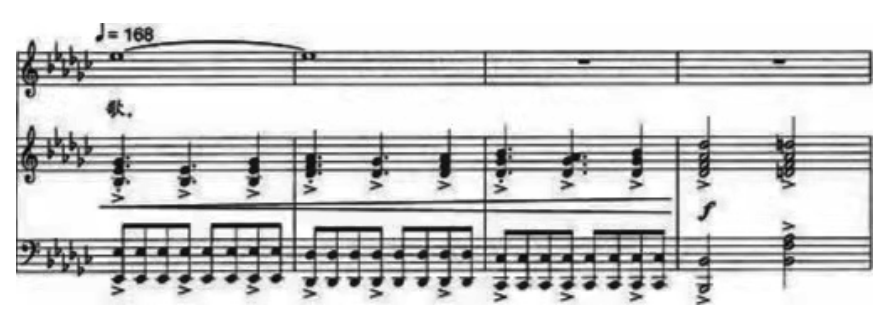

Рис. 7. Интерлюдия на переходе ко второй части.

Смена (ускорение) темпа является важным эмоциональным поворотом всего произведения и ещё одним его ярким моментом. Здесь в мелодической линии появляется второй вид "кусания рыбы за хвост" - "кусающий хвост" между напевом оперы и интерлюдией, которая врывается и образует наложение и последовательность интервалов между различными мелодическими линиями [6].

С точки зрения ритмического рисунка аккомпанемента, это не размер 4\4 в традиционном смысле, а синкопированный ритм латино-американской румбы. Расположение ритмов "в шахматном порядке" (ритмические вертикали и акценты между партиями правой и левой руки) создаёт мощное драматическое воздействие, подготавливая к последующим страстным эмоциям:

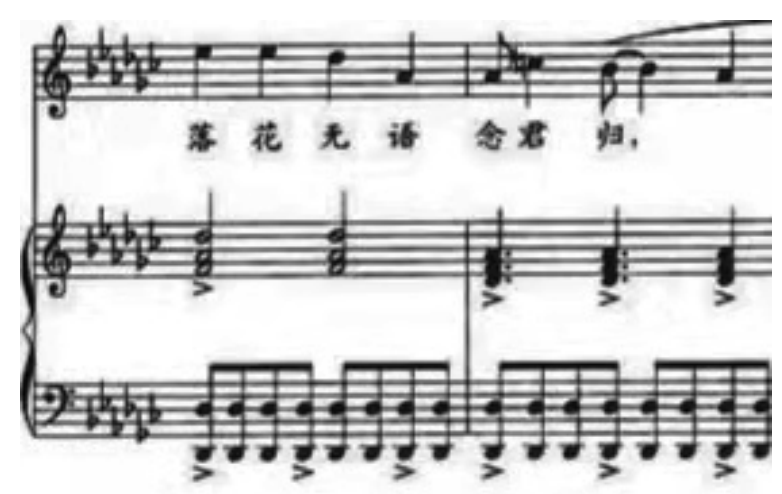

Рис. 8. Характерный ритм аккомпанемента во 2 части песни.

Раздел В состоит из двух частей. В первой части, с точки зрения анализа мелодии, композитор много раз использовал альтерацию (до-бекар), подчёркивающую сдвиг тональности на "яюэ" - музыкальный стиль, относящийся к китайской северной национальной опере. Искусство китайской северной национальной оперы сочетает в себе музыкальные стили национальных меньшинств - таких, как народность Нюйчжэнь и народность Монголы. Прежде всего, это распространенный жанр военных песен, где чувство ритма имеет особенно важное значение [7] и передаётся основными ударными инструментами - гонги, барабаны и пайбань. Аккомпанемент в этой части по-прежнему построен на ритме румбы с сильными, мощными трезвучиями и чистыми октавами для имитации ударных инструментов, воспроизводя страстные и захватывающие эмоции. Концертмейстер должен точно уловить ритм, подчеркнуть атмосферу и управлять эмоциями певца.

Проанализируем фрагмент текста песни:

\section{问花问月问流水, 情在爱在人何在, 落花 无语念君归, 千山万水等你回, 关山梦} 远, 寸寸柔肠心碎。天荒情难绝, 空对月千 行泪, 楼台梦断佳人去不归, 望断天涯山高 水长, 相思漫漫无边。

Рис. 9. Фрагмент текста второй части песни.

\begin{tabular}{|l|c|c|}
\multicolumn{1}{|c|}{ Перевод на русский язык } & Оригинальный текст & $\begin{array}{l}\text { Количество } \\
\text { иероглифов }\end{array}$ \\
\hline $\begin{array}{l}\text { Спросите цветы, спросите луну, } \\
\text { спросите текущую воду, }\end{array}$ & 问花问月问流水 & 7 \\
\hline $\begin{array}{l}\text { Эмоция есть, любовь есть, а человек } \\
\text { где? }\end{array}$ & 情在爱在人何在 & 7 \\
\hline $\begin{array}{l}\text { Опадающие цветы безмолвствуют и } \\
\text { ждут с надеждой вашего возвра- } \\
\text { щения, }\end{array}$ & 落花无语念君归 & 7 \\
\hline
\end{tabular}




\begin{tabular}{|l|c|c|}
\multicolumn{1}{|c|}{ Перевод на русский язык } & Оригинальный текст & $\begin{array}{c}\text { Количество } \\
\text { иероглифов }\end{array}$ \\
\hline $\begin{array}{l}\text { Многочисленные горы и реки ждут } \\
\text { вашего возвращения, }\end{array}$ & 千山万水寻你回 & 7 \\
\hline $\begin{array}{l}\text { Мечта о возвращении в Гуаньшань } \\
\text { очень далеко, }\end{array}$ & 关山梦远 & 4 \\
\hline $\begin{array}{l}\text { Каждый дюйм внутри тела и душа } \\
\text { разрывается }\end{array}$ & 寸寸柔肠心碎 & 6 \\
\hline $\begin{array}{l}\text { Небо пустынно и любви трудно } \\
\text { исчезнуть, }\end{array}$ & 天荒情难绝 & 5 \\
\hline $\begin{array}{l}\text { Одна смотрю на луну, проливаю } \\
\text { потоки слёз }\end{array}$ & 空对月千行泪 & 6 \\
\hline $\begin{array}{l}\text { Открытая терраса на крыше дома, } \\
\text { сон прекратился, красавица ушла и } \\
\text { не вернулась, }\end{array}$ & $\begin{array}{c}\text { 楼台梦断佳人去 } \\
\text { 不归 }\end{array}$ & 9 \\
\hline $\begin{array}{l}\text { Разорви склон неба, } \\
\text { Высокий как гора, и длинный как } \\
\text { река, }\end{array}$ & $\begin{array}{r}\text { 忘断天涯山高 } \\
\text { 水长 }\end{array}$ & 8 \\
\hline Бесконечно скучаю & 相思慢慢无边 & 6 \\
\hline
\end{tabular}

Как мы можем видеть из рисунка 9 и текста, в первых четырёх предложениях используются "семисловные стихи" в жанре поэзии, который заключается в использовании семи иероглифов для формирования предложения. Среди них в первых двух предложениях используется одна и та же мелодия; при этом в первом предложении подчёркивается глагол "спрашивать", а во втором - "эмоция", "любовь" и "человек".

Текст песни полностью выражает крик из глубины сердца, крайнюю тревогу и горе. Посмотрев на количество слов в этом разделе, мы можем обнаружить закономерность "четыре, пять, шесть, семь, восемь, девять". Автор выражает самые страстные эмоции самым лаконичным и красивым языком, в котором заключается неповторимое очарование китайской поэзии.

Во второй части раздела В партия аккомпанемента содержит секстоли (см. рис. 10):

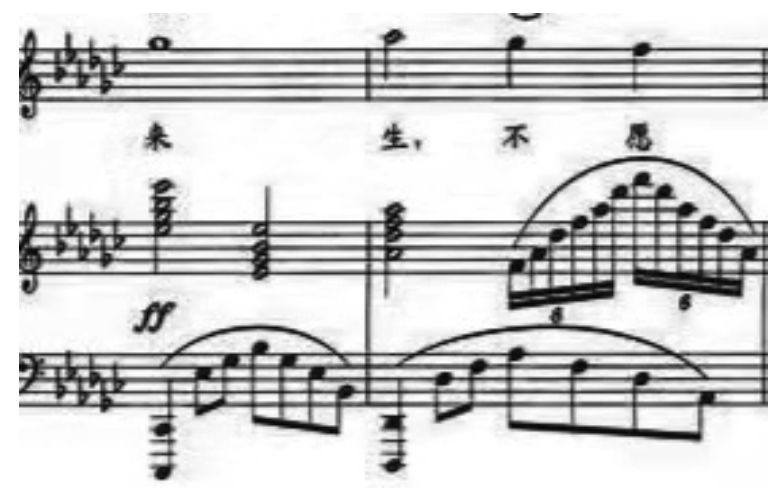

Рис. 10. Появление секстолей в партии аккомпанемента.

а также тремоло и шестнадцатые ноты (рис. 11), имитирующие китайскую пипу, чжэн и саньсянь (китайскую балалайку). Эти три музыкальных инструмента являются основными щипковыми инструментами китайской северной национальной оперы, характеризующимися богатым ритмом, яркими и необузданными тембрами, передачей эмоций персонажей и способностью усилить драматический эффект.

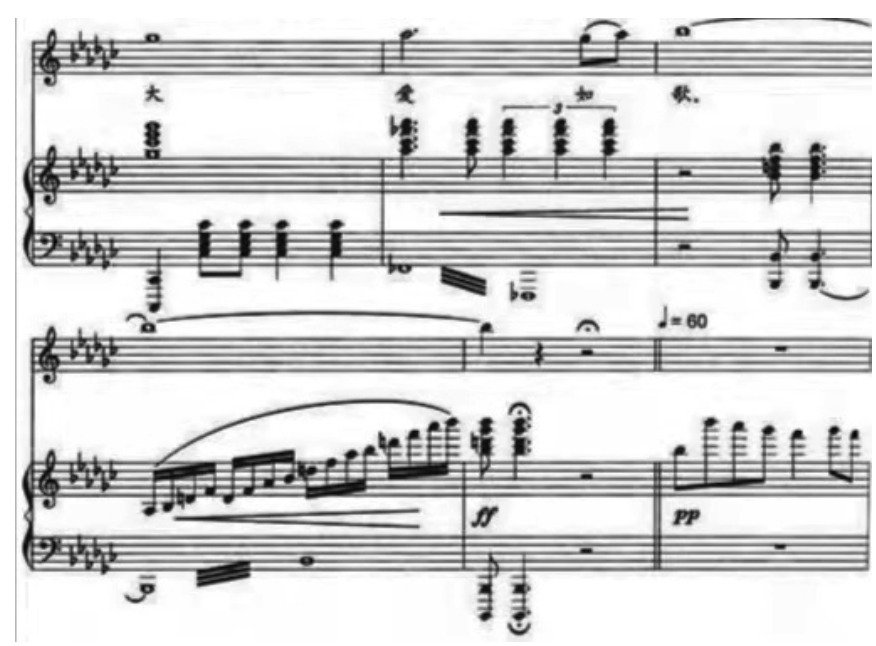

Рис. 11. Тремоло и пассажи шестнадцатых в кульминации.

Анализ вокальной линии позволяет заключить, что это кульминация эмоций. Мелодические линии направлены вверх и устремляются к си-бемолю, останавливаясь на доминантовом аккорде, что придаёт страстность. Эмоции певца и концертмейстера должны быть в высшей степени объединены, чтобы создать эмоциональный накал.

Раздел $\mathrm{A}^{\prime}$ - это отголосок раздела A, передающий эмоцию, которую автор хотел выразить больше всего: "Ничего не хочу, теперь просто хочу получить любовь в этой жизни". Поэтому последняя гармония звучит в тональности ми-бемоль мажор, создавая заключительную эмоциональную кульминацию.

\section{Зак^ючение}

В современной музыкальной среде, будь то Китай или Россия, появилось больше разновидностей музыки со сложным содержанием и разнообразными формами, среди которых есть образцовые и декадентские, кризисные, "нежелательные". Миссия музыкантов - превратить музыку в великое и бессмертное искусство и передать его следующим поколениям. Бессмертие великого искусства всегда неотделимо от неизбежной потери его первоначального поверхностного сознания и его возрождения в духе нового периода [8]. За произведением "Новая песня Лян Чжу" стоит тысячелетняя история китайской культуры и музыки. Это пример современного переписывания музыкантами "бессмертного искусства". Музыканты используют современное мышление, что- 
бы переосмыслить и внести современное содержание и элементы, соответствовать реальности современной жизни [9]. Исходя из эстетики музыки, современные и национальные композиторские техники сочетаются друг с другом, чтобы удовлетворить глубокие духовные потребности современного человека. Такая музыка актуальна, несёт культуру и эстетическое чувство и имеет важное значение для китайской и русской музыки.

ЛИТЕРАТУРА

1. Дэн Яо [Электронный ресурс] // Энциклопедия Baidu. Режим доступа: https://baike.baidu.com/item/\%E9\%82\%93\%E5\%9E\%9A/1250491?fr=aladdin (дата обращения 12.11.2021).

2. Гао Ифэн. Изучение происхождения и творческих особенностей пентатонического стиля [Текст] // Северная музыка. - Ассоциация музыкантов провинции Хэйлунцзян, 2018. - 242 с.

3. Академия музыки Китайской Научно-исследовательского институт [Текст] // Китайский музыкальный словарь. - Пекин: Народное музыкальное издательство, 2005. - 472с.

4. Ляо Шэнцзин. Различные логические отношения в мелодии [Текст] // Журнал Синхайской консерватории. - 2006 (июнь). - №2. - 44 с.

5. Дуань Дежжи. Западная философия смерти [Текст]. - М.-Пекин: Издательство Пекинского университета, 2006. - 550 c.

6. Ли Джити. Введение в анализ структуры китайской музыки [Текст]. - М.-Пекин: Изд-во Центральная консерватория. - 2004.- 98 с.

7. Су Сян. Исследование аккомпанементных инструментов для китайской северной национальной оперы [Текст] // Шаньсийский педагогический университет, 2018. - С. 3-4.

8. Ehrenzweig. Потенциальный порядок искусства [Текст] / Под редакцией Matthew Lipman // Современная эстетика. - М.-Пекин: Изд-во газеты "Гуанминжибао ", 1986. - 420 c

9. Чэнь Цзяньсянь. Народная культура и творческие индустрии [Текст]. - М.-Ухань: Изд-во педагогического университета “Центральный Китай”, 2011. - 11с.

10. "Новая песня Лянчжу". Исполняет Ван Циншуан: https://haokan.baidu.com/v?pd=wisenatural\&vid=4430073223817230608

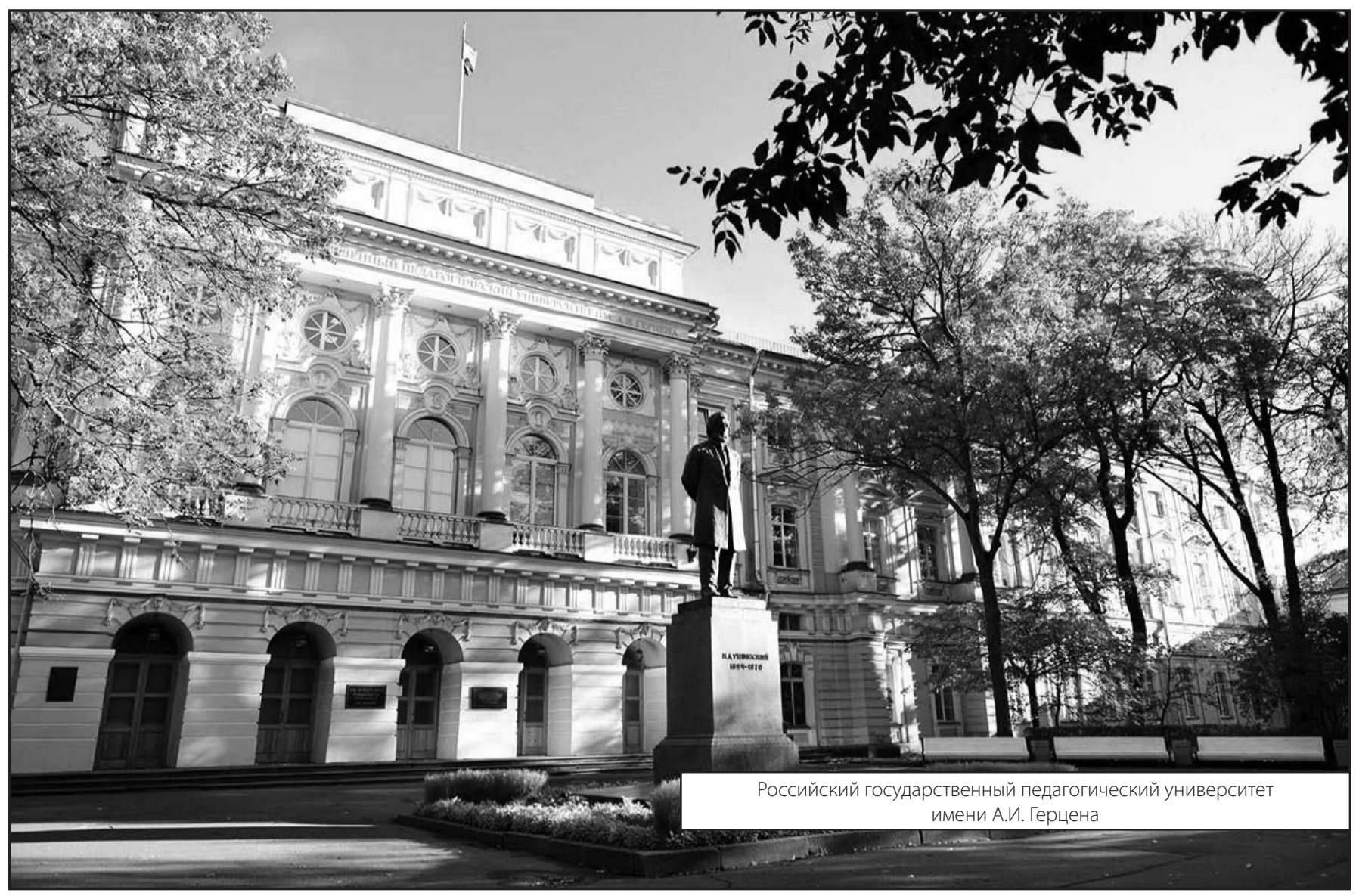

